\title{
PREVALENCE OF LEPTOSPIROSIS IN EGYPTIAN SHEEP FLOCK
}

\author{
ATTIA, E.R.H.; DOHRIEG, R.M.A. and EL-SHAFEI, M.A. \\ Leptospirosis Unite, Animal Reproduction Research Institute (ARRI) \\ Email: sradwanradwan@yahoo.com
}

\begin{abstract}
A sheep flock contains 600 head of Al-Barky ewes suffered from: Icterus, bloody urine, death two days post symptoms appearance and abortion in 6 pregnant ewes. Thesymptoms appeared on 46 case and 6 ewes aborted and mortality rate was 44 case dead. The results of examined samples showed that the isolation of leptospira from 5 out of $52(9.62 \%)$ animals samples (blood, urine and necropsy kidney tissue samples), the isolates were 2 from blood samples (6.7 \%), 2 from kidney samples $(6.7 \%)$ and 1 from urine samples $(10 \%)$. The obtained leptospira isolates from infected ewes were examined by PCR for identification of leptospires, using universal primers set (lig1 / lig2,) that amplify the genomic DNA of all pathogenic Leptospiraserovar only, the most predominant seropositivity using MAT was detected against L.int.icterohaemorrhagiae $(57.69 \%)$, followed by L.int.grippotyphosa $(28.85 \%)$ and L.int.pomona (13.46\%). The highest titer of seropositivity was detected against serovarL.int.icterohaemorrhagiae $(1: 1600)$ while L.int.grippotyphosa and L.int.pomona reached up to (1:400).
\end{abstract}

Received at: 18/3/2014

Key words: Leptospirosis, Egyptian sheep, Prevalence

\section{INTRODUCTION}

Leptospirosis is the most wide spread zoonosis worldwide; it is present in all continents except Antarctica and evidence for the carriage of Leptospira has been found in virtually all mammalian species examined. Humans most commonly become infected through occupational, recreational, or domestic contact with the urine of carrier animals, either directly or via contaminated water or soil. (Adler, and Moctezuma, 2010). Leptospirosis causes production loss in livestock and has emerged as a serious public health concern, especially for livestock owners and workers in the processing industry besides reducing animal production in many countries. The causative organism, a spirochete, was isolated in 1914 from human cases in Japan, and was named Leptospiraicterohaemorrhagiae. It is now known that this is only one of more than 200 pathogenic serovars, distributed between seven species and 23 serogroups worldwide. The epidemiology of leptospirosis involves kidney colonization of a primary (maintenance) host and a secondary host. Primary hosts are often asymptomatic while secondary hosts in most cases will show signs of disease. Both primary and secondary hosts shed leptospires in urine and can transmit the disease to other animals or humans, although human to human cases are rarely reported (Levett, 2001). Symptoms of acute leptospirosis in animals include sudden agalactia in the lactating female, icterus and haemoglobinuria in the young, nephritis and hepatitis in dogs, and meningitis. Chronic leptospirosis can cause abortion, stillbirth, and infertility. Often chronically infected animals remain as asymptomatic carriers for life with the organism localized in the kidneys and in the reproductive organs. In sheep the disease causes high economic loss due to abortion, stillbirth and decreased milk production (Ciceroni et al., 2000).

Few studies were conducted on the diagnosis and control of small ruminants' leptospirosis. Most of the previous studies on this disease reported seropositivities without any isolation of leptospirosis (Lilenbaum et al., 2009). It is obvious from literature that the leptospirosis picture in Egypt is far from complete, and a comprehensive study of infections in farm animals and occupational exposure to the disease is overdue. This is particularly so since the rodents are not controllable in fields and increase silage stores in the farms. The widespread cultivation of bananas and other fruit crops in the wet may result in large numbers of rodent reservoirs of infection and a corresponding link to undiagnosed human and animal illnesses.

The aim of the present work was to study the prevalence of leptospirosis in Egyptian sheep flock suffering from abortion and death. 


\section{MATERIALS and METHODS}

\section{Study Farm Area:}

The farm is located at Cairo-Alex Deseret Road; it contains 600 head of Al-Barky ewes, the animals were fed on a ration contains silage. The farm is Surrounded by other farms and rodents living with large numbers inside and out sides the farm. The symptoms appeared on animals were: icterus, bloody urine, death two days post symptoms appearance and abortion in 6 pregnant ewes. Thesymptoms appeared on 46 case and 6 ewes aborted and mortality rate was44 case dead.

\section{Hygienic measures:}

\section{A) Quarantine of diseased ewes from healthy}

B) Treatment using two regimes of antibiotics were applied to diseased animals, the first was (pen streptomycin) and the second was (pen streptomycin \&panteramycin) two cases respond to the treatment.

C) Sampling for leptosira examination included Tissue samples from dead animals like renal biopsy (with intact capsules), urine, and blood. Sampling was limited to blood and in some cases, free catch urine from live animals.

\section{Laboratory procedures:}

Animals were considered positive for leptospirosis infection if the organism was recovered from culture or when polymerase chain reaction (PCR)-specific assays for pathogenic. Leptospira spp. was positive.
Seropositivity was defined by titers $\geq 1: 200$ for one or more serovars using the microscopic agglutination test (MAT).

Leptospira cultures: Cultures were performed using Ellinghausen and McCullough (1965) modified by Johnson and Harris (EMJH) (1967) base medium (Difco) USA - EMJH Enrichment (Difco) USA broth medium (3-4 tubes/sample) with 5-fluorouracil (200 $\mu \mathrm{g} / \mathrm{mL}$; Difco Chemical Co.) to minimize contamination. Renal tissue was macerated before inoculation into culture media. Only 2-3 drops of blood or urine (undiluted or diluted $1 / 10$ and $1 / 100$ in EMJH broth) were inoculated into the medium. All cultures were incubated at $28-30^{\circ} \mathrm{C}$ for up to 13 weeks. Cultures were examined weekly by dark-field microscopy to detect leptospiral growth.

\section{PCR diagnostic:}

Materials used for DNA extraction, PCR and agarose gel electrophoresis:

- All chemicals and reagents were molecular biology grade.

- Unless otherwise stated, all reagents and buffers were prepared according to Sambrook et al. (1989).

- Oligonucleotide primer: A set of primers were synthesized using MWG oligosynthesis of MWG Biotech (Germany).Oligonucleotide primer used for leptospira DNA amplification according to Raghavan et al. (2004)

$\begin{array}{lll}\text { Primer code } & \text { Primer sequences } & \text { Species specificity }\end{array}$
Lig 1
5'-TCAATCAAAACAAGGGGCT-3'
all pathogenic leptospira

Lig 2

\section{- DNA size markers:}

100 bp DNA ladder (Promega):Cat. No. G2101

It consists of 10 double stranded DNA fragments with sizes of 100 bp DNA ladder.

DNA amplification by PCR was done according to Raghavan et al. (2004) by using specific primers Lig1/Lig2.

\section{Method of DNA extraction and PCR:}

\section{A-Sample preparation and DNA extraction:}

DNA extraction from bacterial culture was performed according to Troyer et al. (1990) as follows:
Bacterial cells of Leptospiral isolates were harvested by centrifugation the culture at $3000 \mathrm{rpm}$ for 15 minute. Each pellet was dissolved in 500 ul volume of TE buffer ( $\mathrm{pH} 7.6$ ) in a microfuge tube. A volume of $400 \mathrm{ul}$ of phenol chloroform (1:1) was added and the mixture was shaken vigorously for 20 seconds. After keeping at $-20^{\circ} \mathrm{C}$ for 30 minutes, the mixture was centrifuged at $12000 \mathrm{rpm}$ for 15 minutes and the aqueous phase was carefully transferred to a clean tube. The phenol-chloroform extraction was repeated once more and the DNA was precipitated by adding 0.1 volume of $3 \mathrm{M}$ sodium acetate $(\mathrm{pH} 5.2)$ and one volume isopropanol. After incubation on ice for at least 30 minutes or at $-20^{\circ} \mathrm{C}$ Over- night, the DNA 
was pelleted down by centrifugation at $12000 \mathrm{rpm}$ for 15 minutes. The DNA pellet was washed with $70 \%$ ethanol. Dried off and dissolved in 30 ul TE buffer.

\section{B- DNA polymerization according to Raghavan et al. (2004):}

PCR was performed in a thermocycler (MWG Primus, Germany) in a total reaction volume of $50 \mu \mathrm{l}$ containing $5 \mu \mathrm{l}$ of $10 \mathrm{x}$ PCR buffer $(100 \mathrm{mMTris}-\mathrm{HCl}$, pH 9.0, $500 \mathrm{mMKCl}, 15 \mathrm{mM} \mathrm{MgCl} 2,1 \%$ Triton X100), $250 \mu \mathrm{M}$ each of the four deoxynucleotide triphosphates, 2 U Taq DNA polymerase (Promega), $10 \mathrm{pg}$ each of the primers derived from the rrs (16S) gene of $L$. Interrogans and $5 \mu$ l of template sample DNA. The reactions were overlaid with $100 \mu 1$ mineral oil and amplification was obtained with one cycle of denaturation at $94^{\circ} \mathrm{C}$ for $3 \mathrm{~min}$., annealing at $63^{\circ} \mathrm{C}$ for $1.5 \mathrm{~min}$ and synthesis at $72^{\circ} \mathrm{C}$ for $2 \mathrm{~min}$., followed by 29 cycles of denaturation at $94^{\circ} \mathrm{C}$ for $1 \mathrm{~min}$., annealing at $63^{\circ} \mathrm{C}$ for $1.5 \mathrm{~min}$ and synthesis at $72^{\circ} \mathrm{C}$ for $2 \mathrm{~min}$. A final extension at $72^{\circ} \mathrm{C}$ for $10 \mathrm{~min}$ was included at the end of the cycles.

\section{C- Agarose gel electrophoresis:}

Gene Amp PCR system 9600 thermal cycler (PerkinElmer Corp., Emeryville, Calif.) was used. Negative control reactions without any template DNA were carried out simultaneously. Gel electrophoresis with
$1.5 \%$ agarose gels was conducted with $1 \times$ TBE buffer (0.1 MTris, 0.09 $\mathrm{M}$ boric acid, $1 \mathrm{mM}$ EDTA) at 4.8 V/cm for 2 h. A 100-bp DNA ladder (Promega Corp., Madison,Wis.) was run concurrently with amplicons for sizing of the bands. Gels were stained with ethidium bromide-TBE solution for $20 \mathrm{~min}$ and the obtained bands were visualized using UV-transilluminator and photographed by a digital camera (FUJI 100). Accurate fragment size analysis based on the electrophoretic mobility of the sample relative to the internal standards (100 bp ladder promega) was achieved by using DNA size analysis Egygene Analyser software.

\section{Microscopic Agglutination Test (MAT):}

The MAT was employed in this study to determine the presence of leptospiral antibodies and their titers in the sera of sheep against 5 leptospiralserovars (L.int grippotyphosa, L.int. Canicola, L.int. Pomona, L.int icterhaemorrhagiae, L.int wolfi.) It was carried out according to Faine et al. (1999). The MAT was performed with living reference leptospira strains cultivated for 7 days in EMJH medium at $30^{\circ} \mathrm{C}$. For serological studies a serial double fold serum dilution was done using Phosphate Buffer Saline (PBS) beginning with dilution 1:100.

\section{RESULTS}

Table 1: Results of Leptospira culture from examined samples:

\begin{tabular}{cccc}
\hline Type of samples & No, of samples & No. of positive isolates & $\%$ \\
\hline Blood samples & 30 & 2 & 6.7 \\
\hline Kidney samples & 12 & 2 & 6.7 \\
\hline Urine samples & 10 & 1 & 10 \\
\hline Total & 52 & 5 & 9.62 \\
\hline
\end{tabular}

Table (1) showed that the isolation of pure isolates were obtained by bacteriological culture of leptospira from 5 out of $52(9.62 \%)$ animals samples (blood, urine and necropsy kidney tissue samples); the isolates were 2 from blood samples $(6.7 \%), 2$ from kidney samples $(6.7 \%)$ and 1 from urine samples $(10 \%)$.

\section{Polymerase chain reaction (PCR) finding:}

The obtained leptospira isolates from infected ewes were examined by PCR for identification of leptospires, using universal primers set (lig1 / lig2,) that amplify the genomic DNA of all pathogenic Leptospiraserovar only as shown in (Photo1). 


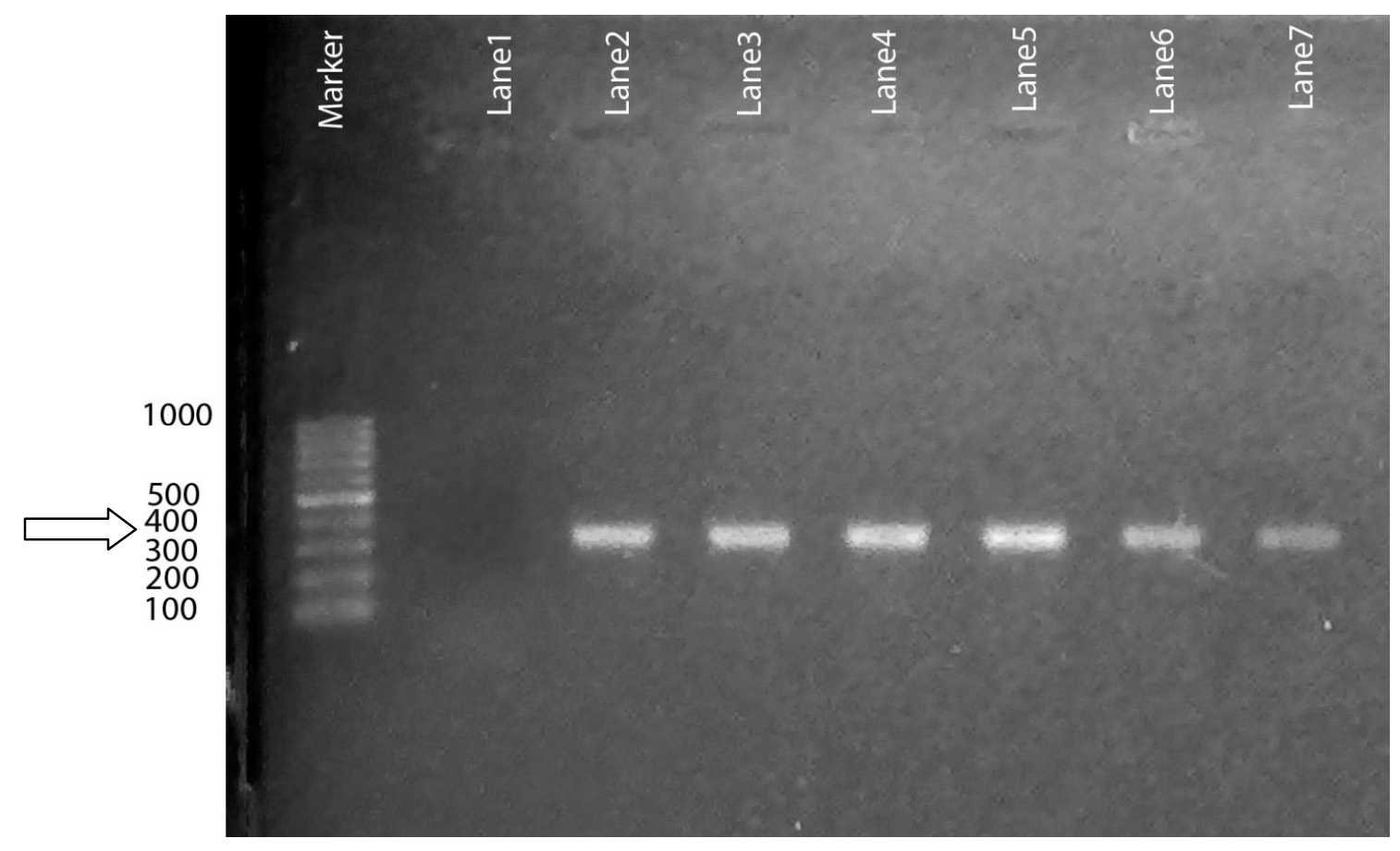

Photo (1): Electrophoretic profile of PCR products of leptospira clinical isolates amplified by using the primer Lig 1\&Lig 2 derived from (16s) gene Marker: ladder 100 bp., Lane (1): Negative control, Lane (2): positive control (L.int.icterohaemorrhagiae), Lane (3): positive isolate sample (1) to (L.int.icterohaemorrhagiae), Lane (4): positive isolate sample (2) to (L.int.icterohaemorrhagiae), Lane (5): positive isolate sample (3) to (L.int.icterohaemorrhagiae), Lane (6): positive isolate sample (4) to (L.int.icterohaemorrhagiae), Lane (7): positive isolate sample to (L.int.icterohaemorrhagiae).

N.B positive control band at $450 \mathrm{bp}$.

Table 2: Results of sero-diagnosis of leptospirosis using MAT among ewes with reproductive disorders:-

\begin{tabular}{|c|c|c|}
\hline \multirow[t]{2}{*}{ Leptospiral Serovars } & \multicolumn{2}{|c|}{ Total cases $n=52$} \\
\hline & No & $\%$ \\
\hline L. int. icterohaemorrhagiae & 30 & 57.69 \\
\hline L.int.grippotyphosa & 15 & 28.85 \\
\hline L.int.pomona & 7 & 13.46 \\
\hline Total & 52 & 100 \\
\hline
\end{tabular}

Table (2) showed that the most predominant seropositivity using MAT was detected against L.int.icterohaemorrhagiae (57.69\%), followed by L.int.grippotyphosa (28.85\%) and L.int.pomona (13.46\%).

Table 3: Distribution of positive titers against different leptospiralserovars among ewes:-

\begin{tabular}{lccccccccc}
\hline \multicolumn{1}{c}{ Leptospiral Serovars } & \multicolumn{8}{c}{ Titers } \\
\cline { 2 - 9 } & & \multicolumn{2}{c}{$1: 200$} & & $1: 400$ & $1: 800$ & $1: 1600$ \\
\cline { 2 - 9 } & No & No & $\%$ & No & $\%$ & No & $\%$ & No & $\%$ \\
\hline L. int. icterohaemorrhagiae & 30 & 9 & 30 & 10 & 33.3 & 10 & 33.3 & 1 & 3.33 \\
\hline L. int. grippotyphosa & 15 & 4 & 26.7 & 11 & 73.3 & & & & \\
\hline L. int. Pomona & 7 & 5 & 71.4 & 2 & 28.6 & & & & \\
\hline
\end{tabular}

Table (3) show that the highest titer of seropositivity was detected against serovars L.int.icterohaemorrhagiae (1:1600), while L.int.grippotyphosa and L.int.pomona reached up to (1:400). 


\section{DISCUSSION}

Leptospirosis is an anthropozoonose, transmissible to humans, caused by a spirochete of the genus Leptospira that lives mainly among rodents and also in wetlands. It occurs worldwide, particularly in Asia, Latin America and Africa. In Europe, the incidence is low (except in France and Great Britain, where its frequency has increased in recent years) but the frequency may be underestimated. Its diagnosis is difficult because of the clinical polymorphism. Early diagnosis of leptospirosis allows effective medical care, improving patient outcomes (Assez et al., 2013). Few studies were conducted on the diagnosis and control of small ruminants' leptospirosis.

This study was conducted on a sheep flock consisted of 600 head of al-Barky ewes lived in a farm located at Cairo-Alex Deseret Road and is Surrounded by many Farms of Cattle and sheep. The borders of that farm were not closed and many rodents and dogs entered and escaped inside the farm and reached to water tanks and food stores. It was known that rodents and dogs were carrier for leptospirosa and shedding leptospira in Urine, so water and food were contaminated by leptospira which lead to an outbreak of leptospirosis.

The control of this out-break included many steps as Quarantine of diseased ewes from healthy in a separate yards, Treatment by using two regimes of antibiotics were applied to diseased animals, the first was (pen streptomycin) has no effect and the second was (pen streptomycin \& panteramycin) has weak effect where two cases responded to the treatment this may be due to most diseased ewes reached a sever stage of leptospirosis and mortality rate increased.

The obtained results as shown in table (1) and Photo (1) showed that a total 52 blood, urine samples and necropsy kidney tissue samples were examined by culture. Table (1) showed that the isolation of leptospira from 5 out $52(9.62 \%)$ animals samples, the isolates were 2 from blood samples $(6.7 \%), 2$ from kidney samples $(6.7 \%)$ and 1 from urine samples $(10 \%)$. In the present study we applied conventional PCR, using universal primers set (lig1/lig2) that amplify the genomic DNA of all pathogenic Leptospira serovars only. The obtained results were considered the first report of isolation of leptospira from sheep in Egypt.

Our results run parallel with that obtained by Lilenbaum et al. (2009) who examinedthirteen goat herds and seven sheep flocks for leptospirosis located in the state of Rio de Janeiro, Brazil, they screened for leptospirosis. From the three herds and three flocks with greatest sero-reactivity by MAT, 19 and 40 seropositive goats and sheep, respectively, were selected, and urine samples were collected for bacteriology and PCR. For both species of animals, the most prevalent reactions were due to serogroups Sejroe and Shermani. Although leptospires were observed by dark-field microscopy in eight samples, pure isolates were obtained by bacteriological culture from only two samples, once infected, both male and female sheep can present leptospires in the renal tissue, and reproductive system (Leon-Vizcaino et al., 1987; Lilenbaum et al., 2008), emphasized the high importance of sheep as a carrier of these serovars. Lilenbaum et al. (2009) observed a high frequency of the serovars Sejroe (17/40, 42.5\%), Shermani (11/40, 27.5\%), Grippotyphosa (4/40, 10\%), Icterohaemorrhagiae $(4 / 40,10 \%)$ and Autumnalis $(3 / 40,7.5 \%)$, which are common in humans, dogs and wild rodents. Besides serology, those authors detected positive results by Dark Field Microscope (DFM) and PCR in four cases only.

Our results opposite to what obtained by Stephen et al. (2011) who reported that sheep were negative for leptospirosis by all laboratory methods used, suggesting that this species may not be an important reservoir of leptospires in the Mahalla region. Early studies in Egypt revealed that $4.2 \%$ of sheep were seropositive (Sebek et al., 1989). This discrepancy may be caused by differences in localities screened, number of animals used, or laboratory testing methods.

Table (2) showed that the most predominant seropositivity using MAT was detected against L.int.icterohaemorrhagiae $(57.69 \%)$, followed by L.int.grippotyphosa $(28.85 \%)$ and L.int.pomona $(13.46 \%)$. Table (3) showed that the highest titer of seropositivity was detected against serovars L.int.icterohaemorrhagiae (1:1600) while L.int.grippotyphosa and L.int.pomona reached up to (1:400). The obtained results run parallel with that obtained by DeCarvalho et al. (2013) who reported that their study was conducted to determine leptospirosis sero-prevalence in sheep and their spatial distribution as well as identify risk factors associated with seropositivity in sheep from 37 herds and 11 municipalities in the Presidente Dutra microregion, Maranhão state, Brazil. They analyzed 379 blood serum samples using a Microscopic Agglutination Test (MAT). The individual seroprevalence was $32 \%$. Of the 37 herds studied, 30 $(81 \%)$ had at least one seropositive animal. In seven municipalities, they observed infection in $100 \%$ of the herds. The serovars recorded were Grippotyphosa (67\%), Wollfi with Hardjo (9\%), Bratislava (9\%), Hardjo (5\%), Icterohaemorrhagiae (5\%), Pomona (2\%), Castellonis (2\%) and Copenhageni (0.8\%). The risk factors are rodents, dogs and the animals' water source. Although a number of nonspecific symptoms such as fever, jaundice, abortion, pink stained milk, haemoglubinuria in cows, and stillbirth and agalactia in sheep may be considered to be the 
clinical signs of the disease (McBride et al., 2005), definitive diagnosis relies on the detection of antileptospiral antibodies in serum samples (Radostits et al., 2007). In other words, the efficacy of leptospira control programs in farm animals relies mainly on the direct identification of carriers (De NardiJúnior et al., 2010; Schonman et al., 2010). (Rajeev et al., 2010), Lucheis and Ferreira (2011) reported that the clinical signs of infection may vary depending on the serovar and host. In maintenance hosts, antibody production is generally low; there are relatively mild signs of the disease, and a prolonged carrier state with organisms in the kidneys. In incidental hosts, the disease may be more severe, with high titers of circulating antibodies and a very short or nonexistent renal carrier state. In general, young animals with renal and hepatic failure have more serious infections than adults. Several diseases may produce symptoms similar to those of leptospirosis, so that laboratory confirmation, through microscopic agglutination test, for example, is required. The effectiveness of treatment depends on early diagnosis and appropriate therapy, depending on clinical features, since leptospirosis can develop into chronic liver disease and nephropathy, progressing towards death. The main and most reliable serological detection test of leptospira serovars following 15 days after infection in human and animals was known by MAT (Perret et al., 2005), because this method is based on using live leptospira serovars, and therefore, it is favorable and more accurate than other current tests. In the case of a lack of live serovars, ELISA (Cousins et al., 1991), PCR (Vitale et al., 2005) and FA (Rajeev et al., 2010) would be valuable in the diagnosis of the disease. Some have recommended mixed tests of MAT and PCR as a screening test for diagnosis and eradication of leptspirosis (Lilenbaum et al., 2009).

Picardeau (2013) reported that Leptospirosis has been under-diagnosed because of non-specific symptoms, inadequate surveillance system, and lack of readily available quick and simple diagnostic tests.

In conclusion we emphasize on a significant effort is needed to increase community awareness to use clean water sources for drinking, and cleaning as opposed to using untreated water directly from canals or tanks. Rats and dogs should be humanely eliminated by the local animal control officials, particularly in areas where there is likely contact with other domestic mammalian species (e.g., farms). In addition, effective diagnostic methods should be established as needed, because the disease has been generally undiagnosed and underestimated.

\section{REFERENCES}

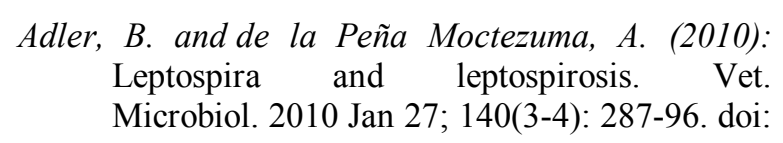

10.1016/j.vetmic.2009.03.012. Epub 2009 Mar 13.

Assez, N.; Mauriaucourt, P.; Cuny, J.; Goldstein, P. and Wiel, E. (2013): [Fever and jaundice... and if it was a leptospirosis. About a case of $L$. interrogansicterohaemorrhagiae in Northern France] Ann FrAnesthReanim. 2013 Jun;32(6): 439-43.

Ciceroni, L.; Lombardo, D.; Pinto, A,; Ciarrocchi, $S$, and Simeoni, J. (2000): Prevalence of antibodies to Leptospiraserovars in sheep and goats in Alto Adige-South Tyrol. J. Vet. Med. B. Infect. Dis. Vet. Public Health. 2000 Apr;47(3): 217-23.

Cousins, DV.; Robertson, GM.; Parkinson, J. and Richards, RB. (1991): Use of the ELISA to detect the $\operatorname{IgM}$ and $\operatorname{IgG}$ antibody response to Leptospirainterrogansserovarhardjo in pregnant ewes, ZentralblBakteriol, 275, 335-42.

De Carvalho, SM. (2013): Leptospirosis seroprevalence and risk factors for sheep in Maranhão state, Brazil. J.Tropical animal health and production.

de NardiJúnior, G.; Genovez, ME.; Ribeiro, MG.; Castro, V. and Jorge, AM. (2010): An in vitro growth inhibition test for measuring the potency of Leptospira spp. Sejroe group vaccine in buffaloes, Biology, 38, 474-8.

Ellinghausen, H.C. and McCullough, W.G. (1965): Nutrition leptospira Pomona and growth of 13 other serotypes. Aserum free medium employing oleic albumn complex. Am. J. Vet. Res., 26:39-51.

Faine, S.; Adler, B.; Bolin, C. and Perolat, P. (1999): "Leptospira and leptospirosis". $2^{\text {nd }}$ ed. Melborne: MediSci. The C.V. Mosby Combany, St. Louis. Baltimore. Philadelphia. Toronto.

Johnson, R.C. and Harris, V.G. (1967): Purin analogue sencitivity and lipase activity of leptospirosis. App.Microbiol., 16 (10); 15841590).

Leon-Vizcaino, L.; Mendoza, M.H. and Garrido, F. (1987): Incidence of abortions caused by leptospirosis in sheep and goats in Spain. Comp. Immunol., Microbiol. Infect. Dis. 10:149-153.

Levett, PN.; Leptospirosis. Clin Microbiol Rev. (2001): 14:296-326.

Lilenbaum, W.; Varges, R.; Brandão, F.Z.; Cortez, A.; de Souza, S.O.; Brandão, P.E.; Richtzenhain, L.J. and Vasconcellos, S.A. (2008): Detection of Leptospira spp. in semen and vaginal fluids of goats and sheep by polymerase chain reaction. Theriogenology 69:837-842.

Lilenbaum, W.; Varges, R.; Ristow, P.; Cortez, A.; Souza, SO.; Richtzenhain,

$L J$. 
and Vasconcellos, SA. (2009): Identification of Leptospira spp. carriers among seroreactive goats and sheep by polymerase chain reaction. Res. Vet. Sci. 2009 Aug;87(1):16-9. doi: 10.1016/j.rvsc.2008.12.014. Epub 2009 Feb 15.

Lucheis, SB. and Ferreira, Jr. Rs. (2011): Ovine leptospirosis in Brazil J. Venom. Anim. Toxins incl. Trop. Dis vol. 17 no. 4.

McBride, AJ.; Athanazio, DA.; Reis, MG. and Ko, AI. (2005): Leptospirosis, Cur Inf Dis, 18, 376-86.

Perret, PC.; Abarca, VK.; Dabanch, J.; Solari, GV.; Garcia, CP. and Carrasco, LS. (2005): Risk factors and frequency of positive antibodies for leptospirosis in a sub urban population near Santiago, RevistaMedica de Chile, 133, 426-31.

Picardeau, M. (2013): Diagnosis and epidemiology of leptospirosis. Med Mal Infect. 2013 Jan; 43(1):1-9.

Radostits, OM.; Gay, CC.; Hinchcliff, KW. and Veterinary Medicine.(2007): A textbook of the diseases of cattle, horses, sheep, pigs, and goats. 10 th Ed. Philadelphia: Saunders, 1094110.

Raghavan, U.M.; Palaniappan, Yung-Fu Chang; Chang, Chao-Fu Chang, M.J.; Pan, C.W.; Yang, Peter Harpending; Sean, P.; McDonough, Edward Dubovi; Thomas Divers; JiaxinQu, Bruce Roe (2004): Evaluation of ligbased conventional and real time PCR for the detection of pathogenic leptospires. Molecular and Cellular probes $19 \mathrm{p}, 111-117$.

Rajeev, S.; Berghaus, RD.; Overton, MW.; Pence, ME. and Baldwin, CA. (2010): Comparison of
FA and MAT for leptospira in pregnant and non-pregnant cows, J Vet DiagInv, 22, 51-4.

Sambrook, J.; Fritsch, F.E. and Maniatis, J. (1989): Molecular cloning: A Laboratory manual. $2^{\mathrm{n}} \mathrm{d}$ ed. Cold Spring Harbor Laboratory Press.

Schonman, L. and Swai, ES. (2010): Herd and animal level risk factors for bovine leptospirosis in Tanga region of Tanzania, Brazilian J Microb, 32, 298-300.

Sebek, Z.; Sixl, W.; Valova, M. and Schaffler, R. (1989): Leptospirosis in man, in wild and in domestic animals at waste disposal sites in Cairo. Geogr Med. Suppl. 1989; 3:141150.[PubMed]

Stephen, A.; Felt, Momtaz, O.; Wasfy, ${ }^{*}$ Wael, F.; ElTras, Ahmed Samir; Bassem Abdel Rahaman; MarieBoshra, Tina M. Parker; Mahmoud EssamHatem; Ahmed Ahmed ElBassiouny; Clinton K. Murray and Guillermo Pimentel (2011): Cross-Species Surveillance of Leptospira in Domestic and Peri-Domestic Animals in Mahalla City, Gharbeya Governorate, Egypt.

Troyer, W.S.; Reed, A.; Oberst, D. and Chengappa, M.M. (1990): A rapid and simplified protocol for DNA isolation from bacteria. Vet. Res. Comm., 14: 447-451.

Vitale, M.; Vitale, F.; Di Marco, V.; Currò, V.; Vesco, G. and Caracappa, S. (2005): Polymerase chain reaction method for leptospirosis, analysis on samples from an autochthon swine population in Sicily, Italy, RevistaCubana de Medicina Tropical, 57, 25-27.

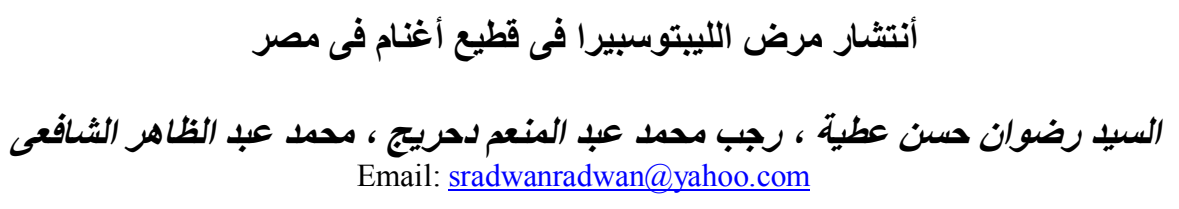

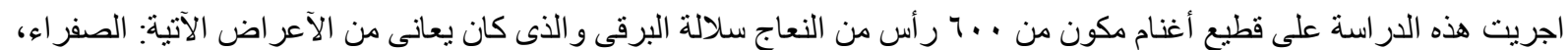

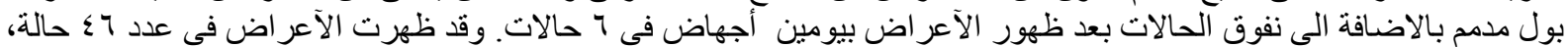

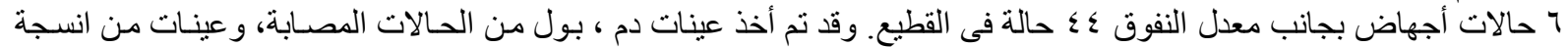

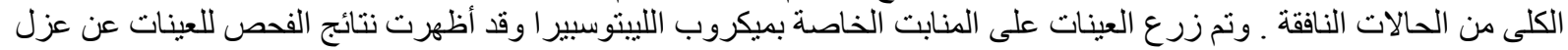

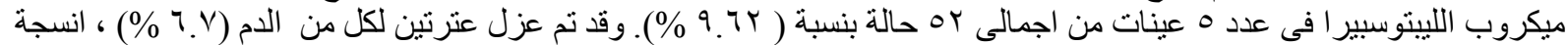

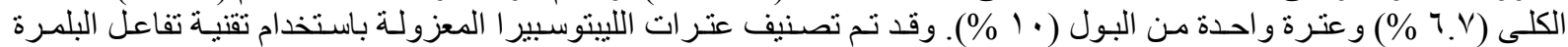

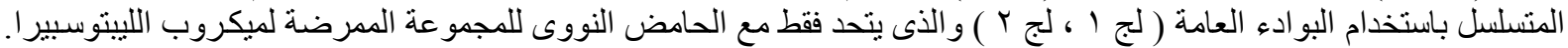

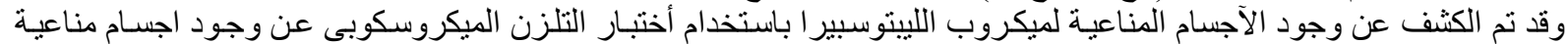

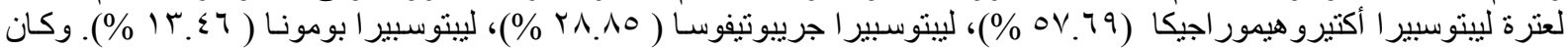

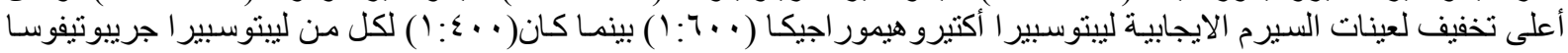
وليبتوسبير ا بومونا. 